\title{
Lifetime occupational exposure to metals and welding fumes, and risk of glioma: a 7- country population-based case-control study
}

Marie-Elise Parent ${ }^{1,2,3^{*}}$ D Michelle C. Turner ${ }^{4,5,6,7}$, Jérôme Lavoué ${ }^{2,3}$, Hugues Richard ${ }^{1}$, Jordi Figuerola ${ }^{4,5,6}$, Laurel Kincl $^{8}$, Lesley Richardson ${ }^{3}$, Geza Benke ${ }^{9}$, Maria Blettner ${ }^{10}$, Sarah Fleming ${ }^{11}$, Martine Hours ${ }^{12}$, Daniel Krewski ${ }^{7}, 13$, David McLean ${ }^{14}$, Siegal Sadetzki ${ }^{15,16}$, Klaus Schlaefer ${ }^{17}$, Brigitte Schlehofer ${ }^{17}$, Joachim Schüz ${ }^{18}$, Jack Siemiatycki ${ }^{2,3}$, Martie van Tongeren ${ }^{19,20}$ and Elisabeth Cardis ${ }^{4,5,6}$

\begin{abstract}
Background: Brain tumor etiology is poorly understood. Based on their ability to pass through the blood-brain barrier, it has been hypothesized that exposure to metals may increase the risk of brain cancer. Results from the few epidemiological studies on this issue are limited and inconsistent.
\end{abstract}

Methods: We investigated the relationship between glioma risk and occupational exposure to five metals - lead, cadmium, nickel, chromium and iron- as well as to welding fumes, using data from the seven-country INTEROCC study. A total of 1800 incident glioma cases and 5160 controls aged 30-69 years were included in the analysis. Lifetime occupational exposure to the agents was assessed using the INTEROCC JEM, a modified version of the Finnish job exposure matrix FINJEM.

Results: In general, cases had a slightly higher prevalence of exposure to the various metals and welding fumes than did controls, with the prevalence among ever exposed ranging between 1.7 and $2.2 \%$ for cadmium to 10.2 and $13.6 \%$ for iron among controls and cases, respectively. However, in multivariable logistic regression analyses, there was no association between ever exposure to any of the agents and risk of glioma with odds ratios ( $95 \%$ confidence intervals) ranging from $0.8(0.7-1.0)$ for lead to $1.1(0.7-1.6)$ for cadmium. Results were consistent across models considering cumulative exposure or duration, as well as in all sensitivity analyses conducted.

Conclusions: Findings from this large-scale international study provide no evidence for an association between occupational exposure to any of the metals under scrutiny or welding fumes, and risk of glioma.

Keywords: Glioma, Occupational exposures, Metals, Welding fumes

\section{Background}

The age-standardized incidence of primary malignant brain tumors is approximately $4.7-5.7$ per 100,000 population worldwide, with rates reported to be higher in more economically developed countries $\left[\begin{array}{ll}1, & 2\end{array}\right]$. Twenty-four percent of brain tumors in adults are

\footnotetext{
* Correspondence: marie-elise.parent@iaf.inrs.ca

${ }^{1}$ Epidemiology and Biostatistics Unit, INRS-Institut Armand-Frappier,

Université du Québec, 531, Boul. Des Prairies, Laval, Quebec H7V 1B7, Canada

${ }^{2}$ School of Public Health, University of Montreal, Montreal, Canada

Full list of author information is available at the end of the article
}

gliomas, with the incidence being slightly higher in men than in women. Glioblastomas and other malignant gliomas represent approximately $75 \%$ of malignant brain tumors [3]. For all ages and subtypes, the 5-year survival rate following diagnosis is between 20 and $30 \%$ in the U.S. [1]. Survival can vary greatly based on subtype, ranging from $3.3 \%$ for glioblastoma multiforme to over $70 \%$ for lower-grade gliomas. Aside from histologic subtype, the best predictor of survival is age at diagnosis, with older patients facing poorer outcomes. 
The etiology of brain tumors is not well understood. Studies on possible risk factors for brain tumors have recently been reviewed [4]. Most studies show an increased risk of brain tumor after exposure to ionizing radiation. Based on positive associations between glioma and exposure to radiofrequency electromagnetic fields (RF-EMF) from wireless phones, RF-EMF have been classified as possibly carcinogenic [5]. Other risk factors that have been investigated include allergies and asthma, certain viruses, previous head injury, genetic factors, diet and smoking. As well, demographic factors such as race, sex and socio-economic status have been explored. To date, however, findings have been largely inconsistent $[1-4,6]$.

Workers in a number of occupations entailing exposure to neurotoxic and carcinogenic compounds have also been studied. Occupational exposure to metals has been of particular interest with respect to brain tumors owing to the ability of several metals to pass through the blood-brain barrier and to be up-taken via olfactory pathways into the brainx [7-9]. An increased risk of glioma has been reported in men with occupational exposures to arsenic, mercury and petroleum products [10]. Lead exposure has been linked to brain cancer mortality $[11,12]$ and glioma incidence [11-13]. In a cohort of Finnish women, elevated risks of brain-nervous system cancer were observed with occupational exposure to iron, chromium, lead and cadmium, albeit none of the risk estimates achieved statistical significance [14]. Brain cancer mortality was found to be elevated among chromium-exposed workers in Japan [15] and welders using chromium-nickel steel [16]. Glioma risk was associated with metal exposure as a group [17]. Other occupational studies document no association between glioma and exposure to metal [18] or lead [19, 20], or between brain cancer and lead [21]. Many of these studies were hampered by small numbers of brain cancer cases, crude occupational histories, or weak exposure information. A recent study reported an increased risk of brain cancer with environmental exposure to lead emissions from petrol [22].

Evaluating associations between occupational exposures and glioma is challenging. Occupational exposures are complex, and can include many different substances at varying concentrations. Therefore, detailed occupational histories and retrospective exposure estimates are required. Due to low incidence, large populations are needed to obtain a sufficient number of glioma cases for study. In earlier studies, this has led some researchers to group all brain tumors together instead of studying specific subtypes which may be linked to different risk factors. Given these issues, associations between glioma and occupational exposures are likely best studied in the context of a large case-control study with detailed occupational histories and exposure estimates.
In the late 1990's, an international case-control study of mobile phone exposure and brain tumors was launched [23]. The INTERPHONE study included data from 13 countries. In addition to a detailed history of mobile phone use, data were collected on a number of other known and possible risk factors, along with detailed occupational histories. Seven of the 13 participating countries, comprising 10 study centers, constituted the INTEROCC study group established to evaluate the role of occupational exposures in brain tumors. Analyses focusing on exposure to solvents, combustion products, dusts and other chemical agents, and extremely low frequency magnetic fields (ELF) have been conducted [24-28]. Risks were close to null for all agents and glioma, other than for ELF which were associated with increased risk. Moreover, an analysis of occupational metal exposure and meningioma risk in INTEROCC [29], including data on 1906 adult meningioma cases and 5565 population controls, suggested positive associations for ever vs. never exposure for several metals with the strongest association observed for iron exposure $(\mathrm{OR}=1.26,95 \%$ CI 1.0-1.58) particularly among women $(\mathrm{OR}=1.70,95 \%$ CI 1.0-2.89). Positive trends emerged for both cumulative exposure and duration. Associations persisted after consideration of other occupational metal co-exposures. In this article, we report on associations between glioma and occupational exposure to five metals- lead, cadmium, nickel, chromium and iron- as well as to welding fumes, using the INTEROCC data.

\section{Methods}

\section{Study population}

The INTEROCC study is a multicenter population-based case-control study including 10 centers from 7 countries (Australia, Canada, France, Germany, Israel, New Zealand and the United Kingdom [UK]) participating in the INTERPHONE study [23]. For most countries, eligible cases were all patients between 30 and 59 years of age and diagnosed with a primary glioma or meningioma tumor between 2000 and 2004. In Germany and the UK, the upper age limit was 69 years while Israel had no upper age limit for recruitment. Only subjects aged 30 to 69 years were included in the present analyses. The procedures for ascertainment of cases and detailed study methods have been described previously [23]. The present analysis is confined to glioma cases. Population controls were randomly selected from electoral lists (Australia, Canada-Montreal, France, New Zealand), population-based registries (Canada-Vancouver, Germany, Israel), patient lists (UK), or random digit dialing (Canada-Ottawa). They were frequency or individually matched to cases by sex, age (within 5 years) and center. In total, 2054 glioma cases and 5601 controls were recruited in the 7 countries. Participation rates were $68 \%$ for glioma cases and 50\% for controls. 


\section{Data collection}

Trained interviewers conducted face-to-face interviews with study participants using a computer-assisted questionnaire. When the study subject had died or was too ill to be interviewed, the interview was conducted with a proxy respondent. Detailed information was collected on socio-economic and lifestyle characteristics (including lifetime use of mobile phones, smoking habits, and occupational history), and medical history [23]. An occupational calendar was used to collect lifetime work histories, covering all jobs held by participants for more than 6 months. It elicited information on the job title, description of tasks, and the start and end year for each job, and, in some countries, company name and description of activities of the company. Each job held by subjects was coded according to international occupation and industry classifications: the International Standard Classification of Occupations editions 1968 (ISCO68 [30]) and 1988 (ISCO88 [31]), and the International Standard Industrial Classification of All Economic Activities, revision 2 (ISIC71) [32]. Common coding guidelines were provided to each center in order to foster homogeneous coding practices. An inter-rater trial was conducted at the start of coding and results were discussed with each center in a further effort to ensure consistency of coding [33].

\section{Occupational exposure assessment}

Occupational exposure to the agents was assessed using a modified version of the Finnish job exposure matrix FINJEM [34]. The Finnish occupation classification system contains 311 major occupational groups and covers the calendar period 1945 to 2003, divided into several sub-periods. FINJEM can translate an occupational history into a history of exposure to about 90 chemical, physical, behavioral, microbiological, ergonomic and psychosocial factors, including the 6 exposures under investigation in this paper. FINJEM provides two exposure estimates for each specific combination of occupation, calendar sub-period, and agent: the proportion of workers in that occupation who were considered to be exposed to the agent $(\mathrm{P})$ and the mean level of exposure among the exposed (L) expressed in units of concentration. When $\mathrm{P}$ was considered to be less than 5\%, the level in FINJEM was set to zero. The estimates of $\mathrm{P}$ and $\mathrm{L}$ were based on exposure measurements, hazard surveys, and the judgements by Finnish occupational hygienists.

Since FINJEM uses the Finnish occupational coding system and the INTEROCC work histories were coded according to international classifications, it was necessary to develop a "crosswalk" between the Finnish codes and the ISCO68. FINJEM was further modified for our purposes with, for example, the time window 1960-1984 split into pre and post-1974 periods. Also, specific FINJEM entries were modified for some of the exposures of interest to increase consistency and specificity of exposure assessment. For instance, FINJEM was modified by using expert-based exposure estimates developed for a population-based case-control study of lung cancer in Montréal. Assignments of exposure were peer reviewed by an international panel of occupational hygienists to ensure that the revised JEM estimates better reflected the prevailing exposure patterns in the seven participating countries. This modified instrument, referred to as the INTEROCC JEM, is described in Van Tongeren et al. [35].

\section{Statistical analyses}

From the 2054 glioma cases and 5601 controls recruited, 1856 cases and 5189 controls met the 30-69 years age restriction. A small number of participants (56 cases, 29 controls) were excluded as they had a personal or family history of neurofibromatosis or tuberous sclerosis, or had missing or erroneous occupational history information, yielding 1800 glioma cases and 5160 controls for analysis.

For each exposure, three indices were defined for the main analysis: i) ever vs. never exposed; ii) lifetime cumulative exposure; and iii) duration of exposure. As noted above, for each job, the INTEROCC JEM provides the probability $(\mathrm{P})$ that a worker in that occupation was exposed to that agent. There are several approaches for deriving an "ever exposure" variable from the INTEROCC JEM. If we designate as exposed to a given agent all those who worked in an occupation with even a small probability of exposure according to the JEM, say as low as $5 \%$, it would be very sensitive, but most of the subjects labelled as exposed would have had a low probability of exposure. At the other extreme, if we use a high value of $P$ as the threshold, say $95 \%$, then it would be very specific, but a large fraction of workers truly exposed would be labelled as unexposed. The trade-off between sensitivity and specificity also has implications for the estimated prevalence of exposure. In order to give greater weight to sensitivity than specificity, but not to exaggerate this choice unduly, we used as the a priori threshold $P \geq 25 \%$. Thus, ever exposure to a given agent was defined as having held at least one job with a probability of exposure of at least $25 \%$ and for at least 1 year. Subjects who had held jobs with a probability of exposure of less than $25 \%$ but greater than $5 \%$, or for less than 1 year were considered to be of "uncertain" exposure status and were assigned to a separate category (not reported). The lifetime cumulative exposure index was defined among ever exposed (corresponding to the ever definition criteria) as the sum of the product of the probability of exposure $(\mathrm{P})$, the level of exposure (L), and the duration for each job held by a subject. The 
continuous cumulative exposure index was categorized according to tertiles of the distribution among exposed controls. We also calculated the total duration of exposure, defined as the sum of the duration of exposure for each job held by a subject (corresponding to the ever definition criteria) minus the possible overlap period between two jobs. To allow sufficient time between occupational exposure and disease onset, all exposures that had occurred within 5 years of the reference date (age at diagnosis for cases and age at interview for controls) were not taken into account, therefore establishing a lag period of 5 years.

For all analyses, the reference category included subjects who had never been exposed to the specific chemical agent of interest. Because of the exploratory nature of these analyses, each exposure was considered independently.

Associations between glioma and each of the 6 exposures (5 metals plus welding fumes) were estimated using conditional logistic regression stratified by sex, age (5-year categories) and center. Further, all analyses were adjusted a priori for the following variables: i) age as a continuous variable (to remove any residual confounding due to age in the strata definition), ii) the maximum education level attained by the subject or her/his spouse (primary, intermediate college, tertiary), iii) the Standard International Occupational Prestige Scale (SIOPS), expressed as a time-weighted average across all jobs [36] iv) antecedents of atopy, defined as ever medical diagnosis of allergy, asthma and/or eczema (recognized as associated with glioma and exposure to metals [37]) and v) the respondent status (subject him/herself vs. proxy respondent).

Missing values for the maximum level of education attained in the household were imputed to the middle category "intermediate college" (14 subjects). Missing values for the SIOPS variable, occurring when the occupation was unknown, were imputed to the median value in the corresponding subject strata of age (5-year categories), sex, center and maximum level of education attained in the household (104 subjects). When variables constituting the "antecedents of atopy" variable were missing (22 subjects), the latter was imputed as "none".

\section{Sensitivity analyses}

Sensitivity analyses were conducted to examine the influence of results using different thresholds for probability of exposure, duration of exposure, and lag period including using alternate probabilities of exposure of $P \geq 5 \%$ and $50 \%$, duration of exposure of 5 years, and lag periods of 1 and 10 years. A separate set of analyses was conducted defining the reference category as never exposed to any metal nor to welding fumes. Further analyses were conducted restricted to: i) male participants; ii) female participants; iii) high-grade glioma cases; iv) glioblastoma cases; and v) participants who completed the study interview without a proxy respondent. Analyses adjusting for cigarette smoking status at diagnosis/ interview (current, ex-smokers, never smokers) and marital status (married vs. others) were also conducted. Sensitivity analyses excluding one by one each of the a priori confounders from the main results model were also performed.

Ethics approval was obtained from all appropriate national and regional research ethics boards, including the Ethical Review Board of IARC (Lyon) for INTERPHONE and the Municipal Institute for Medical Investigation (IMIM) Barcelona for INTEROCC. All participants provided written informed consent.

\section{Results}

The majority of cases $(62.0 \%)$ were males whereas controls were more often females (55.3\%) (Table 1). The mean (standard deviation) age of participants ranged from 50.6 (10.0) to 51.2 (9.7) years among cases and controls, respectively. Participants generally had a primary or secondary level of education, were married, and about half were never smokers. The UK and Germany contributed the majority of participants. Proxy respondents were used for $14.3 \%$ of glioma cases and $0.4 \%$ of controls.

There were high percentages of overlap between exposure to each of the metals and welding fumes (Table 2). In general, cases had a higher prevalence of (ever) exposure to the various metals and welding fumes than controls (Table 3). Exposure prevalence ranged from $1.7-2.2 \%$ for cadmium up to $10.2-13.6 \%$ for iron among controls and cases, respectively.

Associations between exposure to each of the 5 metals and welding fumes, and glioma risk are also presented in Table 3. Once covariates were included in the models, there was no association between ever exposure to any of the agents and glioma risk, with ORs ranging from 0.8 (95\% CI $0.7-1.0)$ for lead to 1.1 (95\% CI 0.7-1.6) for cadmium. There was also no evidence for a trend according to categories of cumulative exposure, including in the highest tertile, where ORs were generally near 1.0. Analyses based on three categories of duration of exposure $(1-4,5-9, \geq 10$ years) yielded similar findings. The only elevated, but non-significant ORs were observed for cadmium, in the second tertile of cumulative exposure $(\mathrm{OR}=1.6,95 \%$ CI $0.9-2.8)$ and among subjects exposed 5-9 years $(\mathrm{OR}=1.4,95 \% \mathrm{CI} 0.6-3.3)$. Some ORs in low exposure categories were non-significantly decreased, as for lead and iron.

Results were similar for all of the agents upon restriction of the analysis to males or to females (results not shown), high-grade glioma cases, glioblastoma cases, or 
Table 1 Selected characteristics of glioma cases and controls, INTEROCC study, 2000-2004*

\begin{tabular}{|c|c|c|}
\hline Variable & $\begin{array}{l}\text { Glioma cases } \\
(n=1800)\end{array}$ & $\begin{array}{l}\text { Controls } \\
(n=5160)\end{array}$ \\
\hline Age, mean (SD) & $50.6(10.0)$ & $51.2(9.7)$ \\
\hline Males, n (\%) & $1116(62.0)$ & $2308(44.7)$ \\
\hline \multicolumn{3}{|l|}{ Education, n (\%) } \\
\hline Primary/secondary & $766(42.6)$ & $2253(43.7)$ \\
\hline Intermediate college/professional & $391(21.7)$ & $1085(21.0)$ \\
\hline Tertiary & $643(35.7)$ & $1822(35.3)$ \\
\hline Proxy respondent, n (\%) & $257(14.3)$ & $23(0.4)$ \\
\hline \multicolumn{3}{|l|}{ Country, n (\%) } \\
\hline Australia & $277(15.4)$ & $665(12.9)$ \\
\hline Canada & $169(9.4)$ & $649(12.6)$ \\
\hline France & $93(5.2)$ & $471(9.1)$ \\
\hline Germany & $366(20.3)$ & $1494(29.0)$ \\
\hline Israel & $282(15.7)$ & $698(13.5)$ \\
\hline New Zealand & $75(4.2)$ & $160(3.1)$ \\
\hline United Kingdom & $538(29.9)$ & $1023(19.8)$ \\
\hline \multicolumn{3}{|l|}{ Tumor histology, n (\%) } \\
\hline Glioblastomas & $848(47.1)$ & - \\
\hline Other & $952(52.9)$ & - \\
\hline $\begin{array}{l}\text { Occupational Prestige Scale } \\
\text { (SIOPS), mean (SD) }\end{array}$ & $43.2(11.5)$ & $44.0(11.8)$ \\
\hline \multicolumn{3}{|l|}{ Marital status, n (\%) } \\
\hline Single & $159(8.9)$ & $431(8.4)$ \\
\hline Married & $1422(79.3)$ & $4035(78.3)$ \\
\hline Divorced & $142(7.9)$ & $494(9.6)$ \\
\hline Widowed & $62(3.5)$ & $190(3.7)$ \\
\hline Don't know & $8(0.4)$ & $5(0.1)$ \\
\hline Missing & $7(-)$ & $5(-)$ \\
\hline \multicolumn{3}{|l|}{ Smoking status } \\
\hline Never & $906(50.3)$ & $2521(48.9)$ \\
\hline Ex-smoker & 386 (21.4) & $1212(23.5)$ \\
\hline Current & $508(28.2)$ & $1427(27.7)$ \\
\hline $\begin{array}{l}\text { Asthma, hay fever, eczema, } \\
\text { n (\%) }\end{array}$ & $416(23.1)$ & $1380(26.7)$ \\
\hline
\end{tabular}

${ }^{*}$ Cases were statistically different from controls at $p<0.05$ in terms of the following variables: age, sex, proxy respondent, country, occupational prestige, marital status, and asthma, hay fever and/or eczema

to self-respondents (Table 3). There was also no evidence for an association according to alternate definitions of $\mathrm{P}$, duration or lag time for any of the agents (Additional file 1: Table S1). This held true when using an unexposed category that excluded exposure to any of the metals under study. Excluding one by one each of the a priori confounders from the main model had a marginal impact on findings. There was no effect modification by education or smoking history (not shown).
Upon further investigation of cadmium according to different durations and probabilities of exposure, and lag times (Additional file 1: Table S1), a significant increase in risk was observed in the first tertile of exposure for a lag of 5 years, a duration $\geq 5$ years and a probability $\geq 5 \%$. Some ORs were greater than one following the various exposure scenarios but no clear pattern emerged and numbers were small.

\section{Discussion}

We investigated the relationship between glioma and occupational exposure to five metals- lead, cadmium, nickel, chromium and iron- as well as to welding fumes, in the seven-country INTEROCC study. Overall, there was no evidence of an association between ever exposure to any of the metals or welding fumes and glioma, with ORs generally near 1.0. No associations were observed according to categories of cumulative exposure or duration of exposure or to a range of alternate assumptions regarding exposure modeling or lag time. Results were consistent across an array of sensitivity analyses.

In the IARC Monograph program on the evaluation of carcinogenic risks to humans, cadmium and cadmium compounds, chromium-6 compounds, nickel compounds, welding fumes, and occupational exposure during iron and steel founding have been classified as human carcinogens (Group 1) while inorganic lead is currently classified as a probably carcinogenic (Group 2A) [38-41]. However, for none of these has the brain been identified as a target site.

Previous results from epidemiological studies examining associations between occupational metal exposure and brain tumors are mixed. An elevated OR was observed among men, but not women, with occupational activities involving metals in a 6-country study of glioma risk $(\mathrm{OR}=1.24,95 \% \mathrm{CI} 0.96-1.62)(n=1178$ cases, 1987 controls), but no association emerged when selfreports of exposure to metal or metal compounds were used [17]. An analysis based on data from the German INTERPHONE study group, which are subsumed in the present analysis, suggested no association between having ever worked in an occupational sector involving metal production and glioma risk or according to duration of work in the sector [18]. One U.S. study including 489 glioma cases and 799 controls reported no overall association between occupational lead exposure as assessed using a quantitative lead exposure database and detailed job-level information [19], although there was some evidence of modification of the association with glioblastoma multiforme by single nucleotide polymorphisms in genes related with oxidative stress [20]. A positive association was observed between occupational lead exposure and brain cancer mortality in the National 
Table 2 Degree of bivariate overlap in exposure to the various metals and welding fumes in INTEROCC, in glioma cases and controls combined, 2000-2004

\begin{tabular}{|c|c|c|c|c|c|c|}
\hline & Cadmium & Chromium & Iron & Lead & Nickel & Welding fumes \\
\hline$n$ & 130 & 537 & 772 & 546 & 659 & 570 \\
\hline Cadmium & - & 7.1 & 6.6 & 10.4 & 7.4 & 2.6 \\
\hline Chromium & 29.2 & - & 69.6 & 40.3 & 79.8 & 66.0 \\
\hline Iron & 39.2 & 100 & - & 64.1 & 95.6 & 100 \\
\hline Lead & 43.8 & 41.0 & 45.3 & - & 44.5 & 53.0 \\
\hline Nickel & 37.7 & 98.0 & 81.6 & 53.7 & - & 82.8 \\
\hline Welding fumes & 11.5 & 70.0 & 73.8 & 55.3 & 71.6 & - \\
\hline
\end{tabular}

${ }^{a}$ Values of cells in each column represent the proportion of participants with exposure to the agent in the column heading who were also exposed to the agent in the corresponding row. For welding fumes, exposures to other metals could come from welding activities, from other activities in the same job and/or from activities in other jobs

Longitudinal Mortality Study (OR for any exposure $=1.56,95 \%$ CI $1.00-2.43$, based on 119 brain cancer deaths) [11]. In a study linking JEM-based exposure to individual metals and the Swedish national cancer register [10], no clear association emerged between occupational chromium/nickel, lead, or metallic compound exposure and glioma risk among 2.8 million men employed in 1970 ( $n=3363$ glioma cases). In contrast, in another study [14], some elevated standardized incidence ratios (SIRs) for brain cancer cancer $(n=693)$ were observed in a cohort of 413,000 Finnish women with blue collar occupations in 1970 entailing exposure to iron $(\mathrm{SIR}=2.15,95 \%$ CI 0.96-4.80), chromium compounds $(\mathrm{SIR}=1.51,95 \%$ CI $0.85-2.67)$, lead $(\mathrm{SIR}=1.27$, 95\% CI 0.81-2.01), and cadmium (SIR $=1.24,95 \% \mathrm{CI}$ $0.72-2.22$ ). There was an elevated risk of brain cancer mortality (standardized mortality ratio $=9.14,95 \% \mathrm{CI}$ 1.81-22.09) in a cohort of 1193 male chromium platers in Japan, although this results was based on only three brain cancer deaths [15]. No association was found with brain cancer mortality in a cohort of 9122 workers with measured blood lead levels in Great Britain, based on 23 brain cancer deaths [42]. There was a positive, though imprecise association between ever occupational exposure to lead dust and fumes, assigned based on a combination of expert intensity ratings and inspection measurements, in a Shanghai general population cohort $(\mathrm{RR}=1.8,95 \% \mathrm{CI} 0.7-4.8, n=77$ incident brain cancer cases).

The cytotoxicity of cadmium has been demonstrated [43]. It can alter the brain function and has been linked to cancer development in experimental animals. Studies on humans are suggestive of associations with cancer sites such as the prostate and the kidney [44], but little evidence has accrued with respect to brain cancer. In our study, cadmium was the only agent showing some risk estimates departing from the null value. However, no clear patterns of risk emerged and this may result from low numbers and statistical instability.
Most studies reporting on welding found no association with brain cancer [45-48]. A suggestive association emerged in a Canadian study of 1009 incident cases of brain cancer and 5039 controls for welding over 20 years or more [49].

Strengths of the current study include the large sample size with 1800 glioma cases and 5160 controls, detailed data on participant lifetime occupational history, objectively assigned exposure estimates, information on potential confounders, as well as information on tumor histology and grade. Nevertheless, we found no evidence of an association between metals or welding fumes, and glioma risk. The null associations observed may reflect various features of the study, including low prevalence and misclassification of exposure. However, associations have been previously been observed in INTEROCC, including between occupational exposure to metal, particularly iron, as well as to oil mist, and risk of meningioma [27, 29]. In contrast with the latter positive findings for meningioma, there were no associations observed for glioma risk here or in other analyses assessing occupational exposure to solvents, combustion products, dusts and other chemical agents overall or according to sex, tumor histology, tumor grade, respondent status, and considering various exposure modeling approaches or lag time [24, 25].

JEMs entail assigning the same set of exposures to all subjects holding a given occupational title. They thus overlook idiosyncratic jobs circumstances that can influence exposure levels. This typically leads to nondifferential misclassification of exposure, diminishing the opportunity to detect a true association [50]. In a casecontrol study of occupational exposure to lead there was moderate agreement in exposure estimates between an expert assessment of detailed work history versus a JEM approach, with the JEM demonstrating higher specificity ( 0.9) than sensitivity $(\sim 0.5)$ [51]. Several steps were undertaken in the study to adapt FINJEM for application to the INTEROCC study, including peer review by an 
Table 3 Adjusted $^{\mathrm{a}}$ odds ratios (OR) and 95\% confidence intervals (Cl) for the risk of glioma and exposure to each of the 5 metals and welding fumes for a duration $\geq 1$ year, a lag of 5 years and $P \geq 25 \%$

\begin{tabular}{|c|c|c|c|c|c|c|c|}
\hline \multirow[t]{2}{*}{ Exposure } & \multirow{2}{*}{$\begin{array}{l}\text { Glioma cases } \\
\mathrm{n}(\%)\end{array}$} & \multirow{2}{*}{$\begin{array}{l}\text { Controls } \\
\text { n (\%) }\end{array}$} & \multirow[t]{2}{*}{ OR $(95 \% \mathrm{Cl})$} & \multicolumn{4}{|l|}{ Lead } \\
\hline & & & & Non-exposed & 1419 (78.8) & $4296(83.3)$ & 1.0 (Ref) \\
\hline Cadmium & & & & Cumulative exposure & $159(8.8)$ & $387(7.5)$ & $0.8(0.7-1.0)$ \\
\hline Non-exposed & $1741(96.7)$ & $5039(97.7)$ & 1.0 (Ref) & $\leq 128.8 \mu \mathrm{mol} / \mathrm{l}$ (in blood) & $45(2.5)$ & $128(2.5)$ & $0.8(0.6-1.2)$ \\
\hline Cumulative exposure & $40(2.2)$ & $90(1.7)$ & $1.1(0.7-1.6)$ & $>128.8$ to $\leq 413.2 \mu \mathrm{mol} / \mathrm{l}$ & $47(2.6)$ & $131(2.5)$ & $0.7(0.5-1.0)$ \\
\hline$\leq 111.4 \mu \mathrm{g} / \mathrm{m}^{3}$ & $12(0.7)$ & $30(0.6)$ & $1.0(0.5-1.9)$ & (in blood) & & & \\
\hline$>111.4$ to $\leq 343.8 \mu \mathrm{g} / \mathrm{m}^{3}$ & $19(1.1)$ & $31(0.6)$ & $1.6(0.9-2.8)$ & $>413.2 \mu \mathrm{mol} / \mathrm{l}$ (in blood) & $67(3.7)$ & $128(2.5)$ & $1.0(0.7-1.3)$ \\
\hline$>343.8 \mu \mathrm{g} / \mathrm{m}^{3}$ & $9(0.5)$ & $29(0.6)$ & $0.7(0.3-1.5)$ & Duration of exposure & & & \\
\hline Duration of exposure & & & & $1-4$ years & $58(3.2)$ & $140(2.7)$ & $1.0(0.7-1.4)$ \\
\hline $1-4$ years & $20(1.1)$ & $44(0.9)$ & $1.1(0.6-1.8)$ & $5-9$ years & $32(1.8)$ & $81(1.6)$ & $0.7(0.4-1.1)$ \\
\hline $5-9$ years & $10(0.6)$ & $19(0.4)$ & $1.4(0.6-3.3)$ & $\geq 10$ years & $69(3.8)$ & $166(3.2)$ & $0.8(0.6-1.1)$ \\
\hline$\geq 10$ years & $10(0.6)$ & $27(0.5)$ & $0.8(0.4-1.8)$ & Restricted to males & $151(13.5)$ & $321(13.9)$ & $0.9(0.7-1.1)$ \\
\hline Restricted to males & $31(2.8)$ & $56(2.4)$ & $1.1(0.7-1.8)$ & High grade cases & $121(9.7)$ & $387(7.5)$ & $0.9(0.7-1.2)$ \\
\hline High grade cases & $25(2.0)$ & $90(1.7)$ & $0.9(0.6-1.5)$ & Glioblastomas & $85(10.0)$ & $387(7.5)$ & $0.9(0.7-1.2)$ \\
\hline Glioblastomas & $18(2.1)$ & $90(1.7)$ & $0.9(0.5-1.5)$ & Self-respondents & $135(8.7)$ & $387(7.5)$ & $0.8(0.7-1.0)$ \\
\hline Self-respondents & $38(2.5)$ & $89(1.7)$ & $1.1(0.7-1.7)$ & Nickel & & & \\
\hline Chromium & & & & Non-exposed & $1534(85.2)$ & 4585 (88.9) & 1.0 (Ref) \\
\hline Non-exposed & $1508(83.8)$ & 4535 (87.9) & 1.0 (Ref) & Cumulative exposure & 215 (11.9) & $444(8.6)$ & $0.9(0.8-1.1)$ \\
\hline Cumulative exposure & $178(9.9)$ & $359(7.0)$ & $0.9(0.7-1.1)$ & $\leq 317.2 \mu \mathrm{g} / \mathrm{m}^{3}$ & $55(3.1)$ & 149 (2.9) & $0.8(0.5-1.1)$ \\
\hline$\leq 445.5 \mu \mathrm{g} / \mathrm{m}^{3}$ & $61(3.4)$ & $121(2.3)$ & $0.9(0.6-1.3)$ & $>317.2$ to $\leq 951.3 \mu \mathrm{g} / \mathrm{m}^{3}$ & $72(4.0)$ & $148(2.9)$ & $0.9(0.7-1.3)$ \\
\hline$>445.5$ to $\leq 3000 \mu \mathrm{g} / \mathrm{m}^{3}$ & $57(3.2)$ & $119(2.3)$ & $0.9(0.6-1.3)$ & $>951.3 \mu \mathrm{g} / \mathrm{m}^{3}$ & $88(4.9)$ & $147(2.8)$ & $1.1(0.8-1.5)$ \\
\hline$>3000 \mu \mathrm{g} / \mathrm{m}^{3}$ & $60(3.3)$ & $119(2.3)$ & $0.9(0.6-1.3)$ & Duration of exposure & & & \\
\hline Duration of exposure & & & & $1-4$ years & $46(2.6)$ & $128(2.5)$ & $0.8(0.5-1.1)$ \\
\hline $1-4$ years & $41(2.3)$ & $95(1.8)$ & $0.9(0.6-1.3)$ & $5-9$ years & $51(2.8)$ & $104(2.0)$ & $0.9(0.6-1.3)$ \\
\hline $5-9$ years & $36(2.0)$ & $81(1.6)$ & $0.8(0.5-1.2)$ & $\geq 10$ years & $118(6.6)$ & $212(4.1)$ & $1.0(0.8-1.3)$ \\
\hline$\geq 10$ years & $101(5.6)$ & $183(3.5)$ & $1.0(0.8-1.4)$ & Restricted to males & 209 (18.7) & $410(17.8)$ & $0.9(0.8-1.2)$ \\
\hline Restricted to males & $175(15.7)$ & $337(14.6)$ & $0.9(0.7-1.2)$ & High grade cases & $155(12.4)$ & $444(8.6)$ & $1.0(0.8-1.2)$ \\
\hline High grade cases & $124(9.9)$ & $359(7.0)$ & $0.9(0.7-1.2)$ & Glioblastomas & $107(12.6)$ & 444 (8.6) & $0.9(0.7-1.2)$ \\
\hline Glioblastomas & $83(9.8)$ & $359(7.0)$ & $0.8(0.6-1.1)$ & Self-respondents & $184(11.9)$ & $443(8.6)$ & $0.9(0.8-1.1)$ \\
\hline Self-respondents & $150(9.7)$ & $358(7.0)$ & $0.9(0.7-1.1)$ & Welding fumes & & & \\
\hline Iron & & & & Non-exposed & 1546 (85.9) & 4606 (89.3) & 1.0 (Ref) \\
\hline Non-exposed & $1546(85.9)$ & $4604(89.2)$ & 1.0 (Ref) & Cumulative exposure & $182(10.1)$ & $388(7.5)$ & $0.9(0.7-1.1)$ \\
\hline Cumulative exposure & $244(13.6)$ & $528(10.2)$ & $0.9(0.7-1.1)$ & $\leq 180 \mathrm{mg} / \mathrm{m}^{3}$ & $63(3.5)$ & $136(2.6)$ & $0.9(0.6-1.2)$ \\
\hline$\leq 70 \mathrm{mg} / \mathrm{m}^{3}$ & $64(3.6)$ & $181(3.5)$ & $0.7(0.5-1.0)$ & $>180$ to $\leq 684 \mathrm{mg} / \mathrm{m}^{3}$ & $54(3.0)$ & $123(2.4)$ & $0.8(0.6-1.2)$ \\
\hline$>70$ to $\leq 254.3 \mathrm{mg} / \mathrm{m}^{3}$ & $81(4.5)$ & $171(3.3)$ & $0.9(0.7-1.2)$ & $>684 \mathrm{mg} / \mathrm{m}^{3}$ & $65(3.6)$ & $129(2.5)$ & $1.0(0.7-1.4)$ \\
\hline$>254.3 \mathrm{mg} / \mathrm{m}^{3}$ & $99(5.5)$ & $176(3.4)$ & $1.1(0.8-1.5)$ & Duration of exposure & & & \\
\hline Duration of exposure & & & & $1-4$ years & $44(2.4)$ & $110(2.1)$ & $0.8(0.6-1.2)$ \\
\hline $1-4$ years & $52(2.9)$ & $139(2.7)$ & $0.8(0.6-1.2)$ & $5-9$ years & $39(2.2)$ & $77(1.5)$ & $0.9(0.6-1.4)$ \\
\hline $5-9$ years & $57(3.2)$ & $116(2.2)$ & $0.9(0.6-1.3)$ & $\geq 10$ years & $99(5.5)$ & $201(3.9)$ & $0.9(0.7-1.2)$ \\
\hline$\geq 10$ years & $135(7.5)$ & $273(5.3)$ & $0.9(0.7-1.2)$ & Restricted to males & $178(15.9)$ & $375(16.2)$ & $0.9(0.7-1.1)$ \\
\hline Restricted to males & $237(21.2)$ & $493(21.4)$ & $0.9(0.7-1.1)$ & High grade cases & $131(10.5)$ & $388(7.5)$ & $0.9(0.7-1.2)$ \\
\hline High grade cases & $181(14.5)$ & $528(10.2)$ & $1.0(0.8-1.2)$ & Glioblastomas & 95 (11.2) & $388(7.5)$ & $0.9(0.7-1.2)$ \\
\hline Glioblastomas & $125(14.7)$ & $528(10.2)$ & $1.2(0.4-3.2)$ & Self-respondents & $157(10.2)$ & 388 (7.6) & $0.9(0.7-1.1)$ \\
\hline Self-respondents & $211(13.7)$ & $527(10.3)$ & $0.9(0.7-1.1)$ & $\begin{array}{l}\text { justed for age, ed } \\
\text { ondent status }\end{array}$ & & & py, and \\
\hline
\end{tabular}

Table 3 Adjusted $^{\mathrm{a}}$ odds ratios (OR) and 95\% confidence intervals (Cl) for the risk of glioma and exposure to each of the 5 metals and welding fumes for a duration $\geq 1$ year, a lag of 5 years and $P \geq 25 \%$ (Continued) respondent status 
international panel of occupational hygienists to ensure that INTEROCC JEM estimates better reflected the prevailing exposure patterns in the seven participating countries [35]. A comprehensive comparison of FINJEM exposure estimates to those potentially encountered in other countries could not be carried out. However, assessments were found to be reasonably comparable to those in a large population-based case-control study in Montreal, especially for metals and welding fumes [52].

Recall bias is always a concern in interview-based studies, but as in this case exposure relied on reporting of the occupational history, similar degrees of accuracy are assumed between cases and controls. There was a relatively high proportion of proxy interviews in the case group, but findings were similar in analyses including and excluding proxy respondents.

As a whole, our study covers ages at diagnosis from 30 to 69 years, with some countries limited to age 59 . Based on the SEER registry, the median age at diagnosis of glioma (all subtypes combined) is 59 years. For all subtypes other than glioblastoma and gliosarcoma, the median age is below that [53]. It is possible that the low numbers for older age groups in our study limited our ability to detect associations for exposures longer than covered here and for subtypes than tend to develop at more advanced ages.

\section{Conclusions}

Findings from this large population-based study using a detailed exposure assessment provide no evidence of an association between lifetime occupational exposure to any of the five metals under study, or to welding fumes, and risk of developing glioma.

\section{Additional file}

Additional file 1: Table S1. Adjusted ${ }^{\mathrm{a}}$ odds ratios (OR) and $95 \%$ confidence intervals $(\mathrm{Cl})$ for the risk of glioma and exposure to each of the 5 metals and welding fumes, according to different durations and probabilities of exposure, and lag times. (DOCX 27 kb)

\section{Abbreviations}

Cl: Confidence interval; ELF: Extremely low frequency magnetic fields; ISCO: International standard classification of occupations; ISIC: International standard industrial classification; JEM: Job exposure matrix; L: Level of exposure; OR: Odds ratio; P: Probability of exposure; RF-EMF: Radiofrequency electromagnetic fields; RR: Relative risk; SIOPS: Standard international occupational prestige scale; SIR: Standardized incidence ratio; UK: United Kingdom

\section{Acknowledgements}

We would like to thank Timo Kauppinen of the Finnish Institute of Occupational Health for allowing us to use and modify the FINJEM as well as sharing his valuable expertise on the exposure assessment committee in the company of Nils Plato of the Karolinska Institute in Stockholm. Rodrigo Villegas of CREAL has contributed to the cleaning and preparing the data for analysis. We would also like to thank Anne Sleeuwenhoek (UK), Avital Jarus-Hakak (Israel), Louise Nadon (Canada) and Florence Samkange-Zeeb (Germany) who coded the occupations and assisted in the data clean-up. We are grateful to Drs Tricia McKinney (UK), Bruce Armstrong (Australia), and Alistair Woodward (New
Zealand) for the use of the occupational data from their INTERPHONE study centres for the INTEROCC project. We thank Deborah Weiss for her help with preparing the manuscript.

\section{Funding}

This work was funded by the National Institutes for Health (NIH) Grant No. 1R01CA124759-01. Coding of the French occupational data was in part funded by AFSSET (Convention N N ST-2005-004). The INTERPHONE study was supported by funding from the European Fifth Framework Program, 'Quality of Life and Management of Living Resources' (contract 100 QLK4-CT-1999901563) and the International Union against Cancer (UICC). The UICC received funds for this purpose from the Mobile Manufacturers' Forum and GSM Association. In Australia, funding was received from the Australian National Health and Medical Research Council (EME Grant 219,129) with funds originally derived from mobile phone service licence fees; a University of Sydney Medical Foundation Program; the Cancer Council NSW and The Cancer Council Victoria. In Canada funding was received from the Canadian Institutes of Health Research (CIHR) (project MOP-42525); the Canada Research Chair programme; the Guzzo-Cancer Research Society Chair in Environment and Cancer; the Fonds de la recherche du Québec Santé; CIHR with partial support from the Canadian Wireless Telecommunications Association; the NSERC Chair in Population Risk Science at the University of Ottawa. In France, funding was received by l'Association pour la Recherche sur le Cancer (ARC) (Contract N85142) and three network operators (Orange, SFR, Bouygues Telecom). In Germany, funding was received from the German Mobile Phone Research Program (Deutsches Mobilfunkforschungsprogramm) of the German Federal Ministry for the Environment, Nuclear 45 Safety, and Nature Protection; the Ministry for the Environment and Traffic of the state of Baden- Wuerttemberg; the Ministry for the Environment of the state of North Rhine-Westphalia; the MAIFOR Program (Mainzer Forschungsforderungsprogramm) of the University of Mainz. In New Zealand, funding was provided by the Health Research Council, Hawkes Bay Medical Research Foundation, the Wellington Medical Research Foundation, the Waikato Medical Research Foundation and the Cancer Society of New Zealand. Additional funding for the UK study was received from the Mobile Telecommunications, Health and Research (MTHR) program, funding from the Health and Safety Executive, the Department of Health, the UK Network Operators (O2, Orange, T-Mobile, Vodafone, '3') and the Scottish Executive.

\section{Availability of data and materials}

The data used for this project is not shared on public repositories for confidentiality reasons. The data can be made available for use in research collaborations by contacting Dr. E. Cardis.

\section{Authors' contributions}

MEP: overall supervision of all aspects of this manuscript, including analytical approach, choice of exposure parameters, interpretation of the findings, manuscript writing. MCT: manuscript writing. JL: exposure assessment. HR: statistical analyses. LR: coordinator involved in study design, exposure assessment and data management. EC: responsible for the coordination of the INTEROCC study, supervision of database management, estimation and validation of exposure coding, participation in analyses and in interpretation of results. Other co-authors: responsible for original data collection and/or for the decisions taken about exposure assessment and analysis strategy, as well as review of the manuscript. All authors read and approved the final manuscript.

\section{Ethics approval and consent to participate}

Ethics approval was obtained from all appropriate national and regional research ethics boards, including the Ethical Review Board of IARC (Lyon) for INTERPHONE and the Municipal Institute for Medical Investigation (IMIM) Barcelona for INTEROCC. All participants provided written informed consent.

Consent for publication Not applicable.

\section{Competing interests}

None declared.

\section{Publisher's Note}

Springer Nature remains neutral with regard to jurisdictional claims in published maps and institutional affiliations. 


\section{Author details}

Epidemiology and Biostatistics Unit, INRS-Institut Armand-Frappier, Université du Québec, 531, Boul. Des Prairies, Laval, Quebec H7V 1B7, Canada. ${ }^{2}$ School of Public Health, University of Montreal, Montreal, Canada. ${ }^{3}$ University of Montreal Hospital Research Centre (CRCHUM), Montreal, Canada. ${ }^{4}$ Barcelona Institute for Global Health (ISGlobal), Barcelona, Spain. ${ }^{5}$ Universitat Pompeu Fabra (UPF), Barcelona, Spain. ${ }^{6}$ CIBER Epidemiología y Salud Pública (CIBERESP), Madrid, Spain. ${ }^{7}$ McLaughlin Centre for Population Health Risk Assessment, University of Ottawa, Ottawa, Canada. ${ }^{8}$ Oregon State University, Corvallis, Oregon, USA. ${ }^{9}$ Monash University, Melbourne, Australia. ${ }^{10}$ Institute of Medical Biostatistics, Epidemiology and Informatics, University Medical Center, Johannes-Gutenberg University Mainz, Mainz, Germany. ${ }^{11}$ University of Leeds, Leeds, UK. ${ }^{12}$ Unité Mixte de Recherche Epidémiologique Transport Travail Environnement Université Lyon 1/IFSTTAR, Université de Lyon, Lyon, France. ${ }^{13}$ School of Epidemiology, Public Health and Disease Prevention, Faculty of Medicine, University of Ottawa, Ottawa, Canada. ${ }^{14}$ Centre for Public Health Research, Massey University, Wellington, New Zealand. ${ }^{15}$ The Cancer \& Radiation Epidemiology Unit, The Gertner Institute, Chaim Sheba Medical Center, Ramat Gan, Israel. ${ }^{16}$ Sackler Faculty of Medicine, Tel-Aviv University, Tel-Aviv, Israel. ${ }^{17}$ German Cancer Research Center (DKFZ), Heidelberg, Germany. ${ }^{18}$ International Agency for Research on Cancer (IARC), Section of Environment and Radiation, Lyon, France. ${ }^{19}$ Institute of Occupational Medicine, Edinburgh, UK. ${ }^{20} \mathrm{Centre}$ for Occupational and Environmental Health, Centre for Epidemiology, University of Manchester, Manchester, UK.

Received: 12 April 2017 Accepted: 15 August 2017

Published online: 25 August 2017

\section{References}

1. Bondy ML, Scheurer ME, Malmer B, Barnholtz-Sloan JS, Davis FG, Il'yasova D, Kruchko C, McCarthy BJ, Rajaraman P, Schwartzbaum JA, et al. Brain tumor epidemiology: consensus from the brain tumor epidemiology consortium. Cancer. 2008;113(Suppl 7):1953-68.

2. Ostrom QT, Bauchet L, Davis FG, Deltour I, Fisher JL, Langer CE, Pekmezci M, Schwartzbaum JA, Turner MC, Walsh KM, et al. The epidemiology of glioma in adults: a "state of the science" review. Neuro-Oncology. 2014;16(7):896-913.

3. McNeill KA. Epidemiology of brain tumors. Neurol Clin. 2016;34(4):981-98.

4. Quach P, El Sherif R, Gomes J, Krewksi D. A systematic review of the risk factors associated with the onset and progression of primary brain tumours. Neurotoxicology. 2016; doi:https://doi.org/10.1016/j.neuro.2016.05.009.

5. Baan R, Grosse Y, Lauby-Secretan B, El Ghissassi F, Bouvard V, BenbrahimTallaa L, Guha N, Islami F, Galichet L, Straif K. Carcinogenicity of radiofrequency electromagnetic fields. Lancet Oncol. 2011;12(7):624-6.

6. Fisher JL, Schwartzbaum JA, Wrensch M, Wiemels JL. Epidemiology of brain tumors. Neurol Clin. 2007;25(4):867-90.

7. Liao LM, Friesen MC, Xiang Y-B, Cai H, Koh D-H, Ji B-T, Yang G, Li H-L, Locke SJ, Rothman N, et al. Occupational lead exposure and associations with selected cancers: the shanghai Men's and Women's health study cohorts. Environ Health Perspect. 2016;124(1):97-103.

8. Sunderman FW Jr. Nasal toxicity, carcinogenicity, and olfactory uptake of metals. Ann Clin Lab Sci. 2001;31(1):3-24.

9. Wang B, Du Y. Cadmium and its neurotoxic effects. Oxidative Med Cell Longev. 2013;2013:898034.

10. Navas-Acien A, Pollan M, Gustavsson P, Plato N. Occupation, exposure to chemicals and risk of gliomas and meningiomas in Sweden. Am J Ind Med. 2002;42(3):214-27.

11. van Wijngaarden E, Dosemeci M. Brain cancer mortality and potential occupational exposure to lead: findings from the National Longitudinal Mortality Study, 1979-1989. Int J Cancer. 2006;119(5):1136-44.

12. Cocco P, Dosemeci M, Heineman EF. Brain cancer and occupational exposure to lead. J Occup Environ Med. 1998;40(11):937-42.

13. Anttila A, Heikkila P, Nykyri E, Kauppinen T, Pukkala E, Hernberg S, Hemmink K. Risk of nervous system cancer among workers exposed to lead. J Occup Environ Med. 1996;38(2):131-6.

14. Wesseling C, Pukkala E, Neuvonen K, Kauppinen T, Boffetta P, Partanen T. Cancer of the brain and nervous system and occupational exposures in Finnish women. J Occup Environ Med. 2002:44(7):663-8.

15. Hara T, Hoshuyama T, Takahashi K, Delgermaa V, Sorahan T. Cancer risk among Japanese chromium platers, 1976-2003. Scand J Work Environ Health. 2010;36(3):216-21.
16. Becker N, Claude J, Frentzel-Beyme R. Cancer risk of arc welders exposed to fumes containing chromium and nickel. Scand J Work Environ Health. 1985;11(2):75-82.

17. Schlehofer B, Hettinger I, Ryan P, Blettner M, Preston-Martin S, Little J, Arslan A, Ahlbom A, Giles GG, Howe GR, et al. Occupational risk factors for low grade and high grade glioma: results from an international case control study of adult brain tumours. Int J Cancer. 2005;113(1):116-25.

18. Samkange-Zeeb F, Schlehofer B, Schuz J, Schlaefer K, Berg-Beckhoff G, Wahrendorf J, Blettner M. Occupation and risk of glioma, meningioma and acoustic neuroma: results from a German case-control study (Interphone study group, Germany). Cancer Epidemiol. 2010;34(1):55-61.

19. Rajaraman P, Stewart PA, Samet JM, Schwartz BS, Linet MS, Zahm SH, Rothman $\mathrm{N}$, Yeager M, Fine HA, Black PM, et al. Lead, genetic susceptibility, and risk of adult brain tumors. Cancer Epidemiol Biomark Prev. 2006:15(12):2514-20.

20. Bhatti P, Stewart PA, Hutchinson A, Rothman N, Linet MS, Inskip PD, Rajaraman P. Lead exposure, polymorphisms in genes related to oxidative stress, and risk of adult brain tumors. Cancer Epidemiol Biomark Prev. 2009;18(6):1841-8

21. Lam TV, Agovino P, Niu X, Roche L. Linkage study of cancer risk among leadexposed workers in New Jersey. Sci Total Environ. 2007:372(2-3):455-62.

22. Wu WT, Lin YJ, Liou SH, Yang CY, Cheng KF, Tsai PJ, Wu TN. Brain cancer associated with environmental lead exposure: evidence from implementation of a National Petrol-Lead Phase-out Program (PLPOP) in Taiwan between 1979 and 2007. Environ Int. 2012;40:97-101.

23. Cardis E, Richardson L, Deltour I, Armstrong B, Feychting M, Johansen C, Kilkenny M, McKinney P, Modan B, Sadetzki S, et al. The INTERPHONE study: design, epidemiological methods, and description of the study population. Eur J Epidemiol. 2007;22(9):647-64.

24. Lacourt A, Cardis E, Pintos J, Richardson L, Klincl L, Benke G, Flemming S, Hours M, Krewski D, McLean D, et al. INTEROCC case-control study: lack of association between glioma tumors and occupational exposure to selected combustion products, dusts and other chemical agents. BMC Public Health. 2013;13(1):340.

25. Benke G, Turner MC, Fleming S, Figuerola J, Kind L, Richardson L, Blettner M, Hours M, Krewski D, McLean D, et al. Occupational solvent exposure and risk of glioma in the INTEROCC study. Br J Cancer. 2017; in press

26. McLean D, Fleming S, Turner MC, Kincl L, Richardson L, Benke G, Schlehofer B, Schlaefer K, Parent ME, Hours M, et al. Occupational solvent exposure and risk of meningioma: results from the INTEROCC multicentre case-control study. Occup Environ Med. 2014;71(4):253-8.

27. McElvenny D, van Tongeren M, MacCalman L, Turner MC, Benke G, Figuerola J, Fleming S, Hours M, Kincl L, Krewski D, et al. The INTEROCC case-control study: risk of meningioma and occupational exposure to selected combustion products, dusts and other chemical agents. Occup Environ Med. 2017; in press

28. Turner MC, Benke G, Bowman JD, Fiquerola J, Fleming S, Hours M, Kincl L, Krewski D, McLean D, Parent ME, et al. Occupational exposure to extremely low-frequency magnetic fields and brain tumor risks in the INTEROCC study. Cancer Epidemiol Biomark Prev. 2014;23(9):1863-72.

29. Sadetzki S, Chetrit A, Turner MC, van Tongeren M, Benke G, Figuerola J, Fleming S, Hours M, Kincl L, Krewski D, et al. Occupational exposure to metals and risk of meningioma: a multinational case-control study. J Neuro-Oncol. 2016;130(3):505-15

30. International Labour Office. International standard classification of occupations, revised edition 1968. Geneva: International Labour Office; 1969.

31. International Labour Office. International standard classification of occupations, revised edition 1988. Geneva: International Labour Office; 1990

32. United Nations. International Standard Industrial Classification of All Economic Activities, Revision 2. In. New York, New York: United Nations; 1968

33. McLean D. Evaluation of the quality and comparability of job coding across seven countries in the INTEROCC study. In: EPICOH 2011: 23rd international conference on epidemiology in occupational health 7-9 September 2011. Oxford, UK: University of Oxford; 2011

34. Kauppinen T, Toikkanen J, Pukkala E. From cross-tabulations to multipurpose exposure information systems: a new job-exposure matrix. Am J Ind Med. 1998:33(4):409-17.

35. van Tongeren $M$, Kincl $L$, Richardson $L$, Benke $G$, Figuerola J, Kauppinen $T$, Lakhani R, Lavoue J, McLean D, Plato N, et al. Assessing occupational exposure to chemicals in an international epidemiological study of brain tumours. Ann Occup Hyg. 2013:57(5):610-26. 
36. Treiman DJ. Occupational prestige in comparative perspective. New York: Academic Press; 1977.

37. Schwensen JF, Bregnbak D, Johansen JD. Recent trends in epidemiology, sensitization and legal requirements of selected relevant contact allergens. Expert Rev Clin Immunol. 2016;12(3):289-300.

38. Cogliano VJ, Baan R, Straif K, Grosse Y, Lauby-Secretan B, El Ghissassi F, Bouvard V, Benbrahim-Tallaa L, Guha N, Freeman C, et al. Preventable exposures associated with human cancers. J Natl Cancer Inst. 2011;103(24):1827-39.

39. Straif K, Benbrahim-Tallaa L, Baan R, Grosse Y, Secretan B, El Ghissassi F, Bouvard V, Guha N, Freeman C, Galichet L, et al. A review of human carcinogens-part C: metals, arsenic, dusts, and fibres. Lancet Oncol. 2009;10(5):453-4.

40. Baan R, Grosse Y, Straif K, Secretan B, El Ghissassi F, Bouvard V, BenbrahimTallaa L, Guha N, Freeman C, Galichet L, et al. Special report: policy. A review of human carcinogens-part F: chemical agents and related occupations. Lancet Oncol. 2009:10(12):1143-4.

41. Guha N, Loomis D, Guyton KZ, Grosse Y, El Ghissassi F, Bouvard V, Benbrahim-Tallaa L, Vilahur N, Muller K, Straif K. Carcinogenicity of welding, molybdenum trioxide, and indium tin oxide. Lancet Oncol. 2017;18(5):581-2.

42. McElvenny DM, Miller BG, MacCalman LA, Sleeuwenhoek A, van Tongeren M, Shepherd K, Darnton AJ, Cherrie JW. Mortality of a cohort of workers in great Britain with blood lead measurements. Occup Environ Med. 2015;72(9):625-32.

43. Mates JM, Segura JA, Alonso FJ, Marquez J. Roles of dioxins and heavy metals in cancer and neurological diseases using ROS-mediated mechanisms. Free Radic Biol Med. 2010;49(9):1328-41.

44. IARC Working Group on the Evaluation of Carcinogenic Risk to Humans. Arsenic, metals, fibres, and dusts. IARC Monogr Eval Carcinog Risks Hum. 2012;100C:11-465

45. Magnani C, Coggon D, Osmond C, Acheson ED. Occupation and five cancers: a case-control study using death certificates. Br J Ind Med. 1987; 44(11):769-76.

46. Ruder AM, Waters MA, Carreon T, Butler MA, Calvert GM, Davis-King KE, Waters KM, Schulte PA, Mandel JS, Morton RF, et al. The upper Midwest health study: industry and occupation of glioma cases and controls. Am J Ind Med. 2012;55(9):747-55.

47. Danielsen TE, Langard S, Andersen A. Incidence of cancer among Norwegian boiler welders. Occup Environ Med. 1996;53(4):231-4.

48. Pukkala E, Martinsen Jl, Lynge E, Gunnarsdottir HK, Sparen P, Tryggvadottir L, Weiderpass E, Kjaerheim K. Occupation and cancer - follow-up of 15 million people in five Nordic countries. Acta Oncol. 2009;48(5):646-790.

49. Pan SY, Ugnat AM, Mao Y. Occupational risk factors for brain cancer in Canada. J Occup Environ Med. 2005;47(7):704-17.

50. Bouyer J, Hemon D. Retrospective evaluation of occupational exposures in population-based case-control studies: general overview with special attention to job exposure matrices. Int J Epidemiol. 1993;22(Suppl 2):S57-64

51. Bhatti P, Stewart PA, Linet MS, Blair A, Inskip PD, Rajaraman P. Comparison of occupational exposure assessment methods in a case-control study of lead, genetic susceptibility and risk of adult brain tumours. Occup Environ Med. 2011;68(1):4-9.

52. Lavoue J, Pintos J, Van Tongeren M, Kincl L, Richardson L, Kauppinen T, Cardis E, Siemiatycki J. Comparison of exposure estimates in the Finnish job-exposure matrix FINJEM with a JEM derived from expert assessments performed in Montreal. Occup Environ Med. 2012;69(7):465-71.

53. Hess KR, Broglio KR, Bondy ML. Adult glioma incidence trends in the United States, 1977-2000. Cancer. 2004:101(10):2293-9.

\section{Submit your next manuscript to BioMed Central and we will help you at every step:}

- We accept pre-submission inquiries

- Our selector tool helps you to find the most relevant journal

- We provide round the clock customer support

- Convenient online submission

- Thorough peer review

- Inclusion in PubMed and all major indexing services

- Maximum visibility for your research

Submit your manuscript at www.biomedcentral.com/submit
Biomed Central 